To cite this article: Guerrero-Solé, F., López-González, H. (2018). Government Formation and Political Discussions in Twitter. An Extended Model for Quantifying Political Distances in Multiparty Democracies. Social Science Computer Review. https://doi.org/10.1177/0894439317744163

\title{
Government Formation and Political Discussions in Twitter. An Extended Model for Quantifying Political Distances in Multiparty Democracies
}

Frederic Guerrero-Solé, Universitat Pompeu Fabra, Barcelona

Hibai Lopez-Gonzalez, Nottingham Trent University, UK

The Retweet Overlap Network (RON) method has proved to be successful in quantifying the distances between political parties in multiparty democracies (GuerreroSolé, Corominas-Murtra \& López-González, 2014; Guerrero-Solé, 2017). These distances are frequently used in political science to explain the formation of coalitions and governments (Volden \& Carrubba, 2004). This paper aims to explore how the data collected from Twitter can be related to the ideological similarities between political parties drawing on an extended development of the RON method that calculates the overlaps between the communities of retweeters of the most influential users in a political discussion. The method is applied to two conversations in Twitter during the last two General Elections in Spain in 2015 and 2016. Our results are consistent with the dynamics and the outcomes of the bargaining processes after both elections, and support Spanish President's statement on the reasonableness of a government of the Popular Party (PP), the Spanish Socialist Workers’ Party (PSOE) and the Citizens-Party of the Citizenry (Cs) (Del Riego, 2016) after the Spanish General Elections in 2016. 
This work links quantitative analysis of the overlaps of the parties' communities of retweeters with the theories of coalition and government formation. It aims to be a contribution to the exploration of Twitter metrics that can be used as new indicators of the support for coalitions in multiparty democracies.

Keywords: Twitter, politics, government formation, Spain, retweet overlap, prediction, coalition formation

Over the past few years there has been a growing debate among scholars on the use of social networks metrics to forecast offline outcomes, in particular in the field of politics and the microblogging site Twitter. Since the publication of Tumasjan et al. (2010) work on the German elections in 2008, and the subsequent critical response in Jungherr, Jürgens and Schoen (2011), the debate has been focused on the usefulness of Twitter metrics to forecast voters' support and, finally, the electoral results. Taking advantage of the relative simplicity of collecting and processing tweets (Jungherr, Schoen and Jürgens, 2016; Vargo, Guo, McCombs, \& Shaw, 2014), scholars have focused on the analysis of how politicians use Twitter (Kim \& Park, 2012; Vergeer \& Hermans, 2013; Plotkowiak \& Stanoevska-Slabeva, 2013; Larsson \& Ihlen, 2015; Graham, Jackson \& Broersma, 2016), people’s reaction to and involvement in politics (Lee, 2013; Park, 2013), the impact of candidate supporters’ posts on media agendas (Parmelee, 2013), the mediation of politics through Twitter (Jungherr, Schoen and Jürgens, 2016), the dynamics of Twitter political coverage (Jungherr, 2014) the relationship between follower-followee and communication networks, and the vote agreement of the US 
members of the congress (Peng, Liu, Wu and Liu, 2016). But above all Twitter datasets have been used to predict electoral outcomes (Tumasjan, Sprenger, Sandner \& Welpe, 2010; DiGrazia, McKelvey, Bollen \& Rojas, 2013), or, on the contrary, to discredit the correlation of Twitter metrics with electoral results (Jungherr, Jürgens \& Schoen, 2011; Tjong, Sang, and Bos, 2012; Skoric, Poor, Achananuparp, Lim \& Jiang; 2012; GayoAvello, 2012; 2013).

While most of the works on the quantitative analysis of Twitter data during political campaigns have been focused on the correlation between Twitter metrics and the elections results, little attention has been paid to relationships between Twitter metrics and other variables such as attention (Freelon, Lynch \& Aday, 2015), public opinion, or support for coalitions (Guerrero-Solé, Corominas-Murtra \& López-González, 2014). Jungherr, Schoen, Posegga and Jürgens (2016) proposed that Twitter-based metrics may be linked to alternative concepts other than political support or opinion polls. In this sense, this paper aims to analyse the relationship between the retweeting behaviour of Twitter users —in particular, the overlaps of the communities of parties' retweetersand coalition and government formation. The starting point is the political context in Spain after the elections in 2015 and 2016 that meant the end of the two-party dominance (Orriols \& Cordero, 2016), and lead to a post-electoral bargaining process between the four main political parties in the country, i. e., the Popular Party (PP), the Spanish Socialist Workers’ Party (PSOE), the Citizens-Party of the Citizenry (Cs)”, and the leftist party We Can (Podemos). The main hypothesis is that if retweeting is a stable behaviour that arises from people's will to endorse someone else's message, then we can find a method to measure to what extent users may endorse two or more parties at 
the same time. This behaviour is then linked to the process of government formation in multiparty political systems,

Retweeting is one of the key functions in Twitter to spread and share information. When a user retweets someone else's tweet, the message appears in the timeline of her followers. There are many authors that sustain that retweeting is basically a form of endorsement (Conover et al., 2011; Williams, McMurray, Kurz \& Hugo Lambert, 2015; Guerrero-Solé, 2017), unless a commentary is added by the retweeter (Bruns \& Burgess, 2012). On the contrary, other scholars suggest that it is an ambiguous practice and can only be partially considered as an approval of others' messages (boyd, Golder \& Lotan, 2010; Hemphill, Otterbacher \& Shapiro, 2013); that there are many determinants of information retweeting (Liu, Liu \& Li, 2012); and that retweeting should be better conceived as an indicator of information diffusion (González-Bailón, Borge-Holthoefer \& Moreno, 2013), or of users’ attention (Freelon, Lynch \& Aday, 2015). Additionally, scholars point out that some users, in particular journalists (Molyneux, 2015; Metaxas, Mustafaraj, Wong, Zeng, Keefe \& Finn, 2015), tend to advise that retweets are not endorsements in a disclaimer in their profiles (Hemphill, Otterbacher \& Shapiro, 2013). However, the act of retweeting may be better understood as an endorsement when it comes to political discussions, and it can become a costly act when the message is explicitly connected to a given ideology (Ceron \& D'Adda, 2015; Ceron, Curini \& Iacus, 2014). 
Another key aspect to be considered in Social Networks is that of homophily. Homophily is understood as individuals' tendency to form social ties with other people who resemble themselves. Homophily refers to any attribute shared by two people (McPherson, Smith-Lovin \& Cook, 2001). Among those attributes, scholars have found that happiness (Fowler and Christakis, 2008) or smoking (Christakis and Fowler, 2008) are characteristics that lead people to form clusters in social networks. Homophily has been observed in political blogs (Adamic and Glance, 2005), online dating platforms (Skopek, Schulz \& Blossfeld, 2011), MySpace (Thelwall, 2010), Facebook (La Fond \& Neville, 2010; Nick, Lee, Cunningham \& Brandes, 2013), and in Twitter (Weng, Lim, Jiang \& He, 2010; Himelboim, McCreery \& Smith, 2013; Xu \& Feng, 2014; Huberty, 2015). The homophilic behavior of users in social networks lead to several consequences. Firstly, the position of a user in the network may affect his attitudes and behaviours (Williams, McMurray, Kurz \& Hugo Lambert, 2015). Secondly, the process of selective diffusion of information is partially governed by homophily (Romero, Meeder \& Kleinberg, 2011), although its power may be overestimated when endogenous network mechanisms, in particular structural factors, are omitted (Peng, Liu, Wu \& Liu, 2016). Despite ideological homophily in the diffusion of non-political information is low (Barberá, Jost, Nagler, Tucker and Bonneau, 2015), it has a strong influence on the diffusion of political messages. One of the consequences is that in political conversations Twitter resembles an echo chamber (Bruns \& Highfield, 2013; Larsson \& Moe, 2013), although outsiders can join these conversations (Ausserhofer \& Maireder, 2013). These echo chambers are thought as mechanisms for reinforcement of users' attitudes and opinions. Thirdly, users' latent attributes can be easily uncovered by making use of simple algorithms (Guerrero-Solé, Corominas-Murtra \& López- 
González, 2014). Finally, the spirals of reinforcement lead communities to a strong polarization (Kim \& Park, 2012) and accentuate pre-existing political bias (Conover et al., 2011).

\section{Political Context in Spain}

Spain has 46.4 million inhabitants represented by 350 members of the Spanish Congress, the lower house of the Spanish Parliament (INE, 2016). Social, economic and political situation in Spain has dramatically changed since the beginning of the economic crisis is 2008. The crisis and its social consequences, such as the burst of activism in 2011 (the so-called 15-M or indignados movement), along with unemployment, political corruption, and the rise of separatism in Catalonia have marked Spanish politics (Casero-Ripolles, Feenstra \& Tormey, 2016). All these ingredients have led to the development of new political parties (Mico and Casero-Ripolles, 2014) that have broken the traditional two-party system (Orriols \& Cordero, 2016). A first sign of this break was the results of the European elections in May 2015. Both traditional parties, PP and PSOE, lost support, while new entrants such as Podemos and Cs became close third and fourth.

European election in May 2015 were just a preface of what was going to come later. The results of the Spanish general election in December $20^{\text {th }}$ confirmed that no party would have the majority in the Congress, and more than two parties were needed to reach the minimum of 176 seats to form a new government (for all the possible alternatives for an investiture, see Simón, 2016). The Spanish King, Felipe VI, offered PP’s leader and acting president Mariano Rajoy to present his candidacy to the Congress, but Rajoy rejected the offer since he had no other support than that of the 
deputies of his own party. Cs did not want to pact with a leader that was stained by corruption (Rajoy), and decided to support the PSOE leader. Cs and PSOE signed an agreement to support Pedro Sánchez to become the Spanish president in March, 2016. It provoked to radical left party Podemos to drift apart from PSOE, and to right wing PP from Cs. Before the agreement, PSOE and Podemos were considered as ideological allies in the formation of a new government in Spain, and so did PP and Cs. Both parties, PSOE and Cs represented only 130 deputies of the 350 in the Spanish Congress. However, they considered that they were forced to present the candidacy and show to the Spaniards that PP was not the only capable party to rule the country. This alliance broke the hypothetical bonds of trust between the left parties on one side, and the right parties on the other, being considered by many party members and voters as a contra natura alliance (see Table 1 for ideological position of each party).

However, the formation of a government after the 20D elections was constrained by the complexity of the bargaining process, the uncertainty related to the high level of electoral volatility, and the emergence of new parties (Simón, 2016). Finally, no party reached the minimum required seats and Spanish citizens returned to polls in June $26^{\text {th }}$ 2016.

\section{Table 1}

The results of the second general election in half a year followed the same pattern as in December (Table 2), and the problem of forming a government was to be solved (Simón, 2016). Despite PP picked up 14 extra seats, at least three parties were needed to form a new government. However, this second time it was the acting PM and PP's 
leader, Mariano Rajoy, who signed an agreement with Cs and presented his candidacy to the Spanish Congress. As Sanchez did six months before, Rajoy lost investiture debate (Jones, 2016) and if a resolution was not reached, a third general election was to be scheduled for mid-December 2016. Spanish acting PM Mariano Rajoy considered that the most reasonable solution would be a coalition between PP, PSOE and Cs (the Spanish grand coalition) (del Riego, 2016). Unlike Podemos, the three parties were defenders of the constitutional order in Spain and were against the recognition of Catalonia as a nation and, consequently, against the celebration of a referendum for its independence. However, Pedro Sánchez, the leader of the PSOE, was thinking about reaching an agreement with the leftist Unidos Podemos after the 2016 elections (Juliana, 2016), despite any combination including Podemos would mean the acceptance that Spain can also be governed by forces that are against the constitutional order. In summary, Spain had to find its way out of the political paralysis it was facing since December 2015. Finally, Rajoy returned to office with the support of Cs and the abstention of PSOE, while Pedro Sánchez resigned as leader of PSOE.

\section{Table 2}

\section{Government formation and ideological distance}

When no single party wins an absolute majority, parties have to negotiate to achieve a parliamentary majority (Schleiter, Belu \& Hazell, 2017). Within this context, the factors that can influence the formation of a government or a coalition have to be taken into 
account. Even more, if we consider that when new parties enter parliament, uncertainty is aggravated (Grotz \& Weber, 2016). The processes of government formation have been vastly analysed by scholars in political science (Ceron, 2014; Mölder, 2017), and it is a central field in comparative political science (Debus, 2009). However, this theoretical productivity has failed in explaining and predicting the formation of realworld governments (Martin \& Stevenson, 2001). One of the main factors that contribute to the explanation of coalition formation is that of the ideological distances between parties (Volden \& Carrubba, 2004). Differences between parties have been usually estimated in terms of ideological distance (Mölder, 2017). These distances can have a psychological meaning for political actors (Grofman, 1982; Laver, 1998). In this sense, it has been shown that the increase of this distance makes coalition formation more difficult (Hinckley, 1972; Bäck \& Dumont, 2008, Vercesi, 2016). Besides, parties that are ideologically close are more likely to share overlapping voters (Martin \& Vanberg, 2003), and they are driven to assess possible coalitions drawing on their expectations about the closeness of the future government with their own political positions (Bäck, 2003). On the contrary, other studies show that the likelihood to form a government does not necessarily depend on the ideological division between parties (Martin \& Stevenson, 2001). Nevertheless, the elements that have been traditionally used in coalition studies can’t fully explain the process of government formation, and new methods such as statistical analysis are needed (Bäck \& Dumont, 2007).

\section{The present study}

Social networks have become communication technologies to bring about practical action in politics. In particular, Twitter has become the centre of online political 
discussions, and a terrain in which people share their thoughts and others' thoughts through retweeting in their everyday life actions. The aim of this research is to analyse to what extent the data collected from Twitter can be used to measure the political distances between parties, and, consequently, the likelihood of a given coalition to succeed in the bargaining process after the elections. Previous literature in coalition formation has found that people consider their coalition preferences when voting (Plescia \& Aichholzer, 2017), and that coalition signals facilitate strategic coordination among voters (Gschwend, Stoetzer, \& Zittlau, 2016).

We draw on the Retweet Overlap Network (RON) method to propose a metric to establish what can be considered as the most feasible coalitions in terms of overlaps. We analyse the political conversations in Twitter in the electoral campaigns of 2015 and 2016. With that aim in mind, two neutral hashtags, \#26J and \#20D, were selected. Firstly, we analyse the retweeting behaviour of users in both conversations and the retweet networks. Considering the characteristics of the Twitter networks previously described, the main objective of this paper is to analyze to what extent the overlaps between the communities of retweeters of politicians and political parties can provide us with information about the closeness between parties and, consequently, use these data for future models for forecasting the outcomes of bargaining post-electoral processes in multiparty political systems. The rationale under the hypothesis draws on the fact that if retweets are mainly endorsements and the networks have an homophilic nature, then the overlaps of retweeters could be related to the ideological closeness or distance between parties. Thus, our two first hypotheses are as follows: 
H1: The retweet network will show the homophilic behavior of the users.

H2: The retweet overlaps can be used as a measure for political distances between parties.

Since different types of users can understand differently the meaning of a retweet (Molyneux, 2015), and show different retweeting behavior, we finally extended the RON method and calculated the overlaps gradually excluding politicians, media and journalists of the communities of retweeters. Consequently, our first research question is then:

RQ1: Do the values of the political distances depend on the typology of the users considered in the RON method?

\section{Method}

\section{Sample description}

The Twitter API Search was used for collecting the tweets. For the first sample, we collected all the tweets containing the neutral hashtag \#20D; for the second those containing the neutral hashtag \#26J (see Table 3). Both hashtags were intermittently trending topics in Spain and were used by political parties, media, journalists and citizens to tag their messages. According to Cohen and Ruths (2013), the use of neutral hashtags to analyse political conversations is absolutely justified since researchers can avoid strong correlations with political leanings. In that sense, Boutet, Kim and Yoneki 
(2012) found that non-neutral hashtags related to the UK 2010 election were highly dependent on their meaning, while the usage rates of neutral hashtags remained at a similar level among political parties. Other studies have focused on neutral hashtags as a way to analyse the dynamics of political communication in Twitter (Jungherr, 2014).

\section{Table 3}

For each tweet, we collected its unique identifier, username and self-description of the author, the body of the tweet, that contains users' mentions and retweets, links and hashtags, the date and hour the message was posted, and the number of followers of the user. Afterwards, we created a register for every user participating in the debates, and calculated the number of tweets, retweets and replies posted by user, and the number of times the user was mentioned, retweeted or replied. Once the users' database was created, we classified them by politicians and political parties, media outlets, journalists, citizens and others (D’heer \& Verdegem, 2014; Guerrero-Solé \& MasManchón, 2017). We used users’ self-description to manually classify the users top 5000 most retweeted users in the database (Table 4). Since influence in terms of the number of times a user is retweeted follows a power law distribution (Clauset, Shalizi \& Newman, 2009; Guerrero-Solé, 2017), they can be considered as the most influential users of the network.

\section{Table 4}


By analysing their name and self-description, we also classified political accounts by party (Table 5) and calculated the number of retweets received by each party (Table 6).

\section{Table 5}

\section{Table 6}

Once we classified the most retweeted users in both networks, we first calculated the number of retweets received by party that came from members of the same party and from members of the other parties. Afterwards, we built the retweet network (Conover et al., 2011; Peng, Liu, Wu \& Liu, 2016) to visualize to what extent parties showed homophily in retweeting. Afterwards, we applied the Retweet Overlap Network (RON) method developed by Guerrero-Solé (2017). We identified the communities of retweeters of every user, and calculated the intersection between those communities using the Jaccard coefficient, and defined the matrix $\mathrm{M}_{\mathrm{ij}}$ as follows:

$$
M_{i j}=\sigma\left(C_{i}, C_{j}\right)=\left|C_{i} \cap C_{j}\right| /\left|C_{i} U C_{j}\right|
$$

$\mathrm{M}_{\mathrm{ij}}$ ranges from 0 to 1 , being $C_{\mathrm{i}}$ and $\mathrm{C}_{\mathrm{j}}$ the communities of retweeters of two given users $\mathrm{i}$ and $\mathrm{j}$. Then, we applied a sequence of thresholds to the matrix to obtain a sequence of nested subgraphs that were used to compel the emergence of the community structure of the network. This first method was only used to prove how fragmented the network of 
the most retweeted users was, being the intersection of communities the metric used to build the edges between them.

\section{Extended RON}

When the RON method was first developed, the authors did not take into account any of the characteristics of the members of the communities of retweeters, nor the characteristics of the most retweeted users themselves. In response to that, we extend the RON method to improve the accuracy and the interpretation of the values of the overlaps, by selecting only those users that meet a given set of characteristics. Thus, in a second step, we defined

$A_{N j}=\left\{A_{1}, A_{2}, \ldots A_{j}\right\}$ as the set of $j$ attributes of a given community of users $N$. We then selected two different communities:

$\mathrm{N}_{\mathrm{T}}$ as the community of the most retweeted users,

and $\mathrm{N}_{\mathrm{R}}$ as the community of all the users that retweeted those $\mathrm{N}_{\mathrm{T}}$ users.

Afterwards, we defined

$\mathrm{n}_{\mathrm{Ti}}$ as the subset of users in $\mathrm{N}_{\mathrm{T}}$ that shared a common subset of attributes $\mathrm{A}_{\mathrm{NTi}}$,

$n_{R j}$ as the subset of users in $N_{R}$ that shared a common subset of attributes $A_{N R j}$, and, $\mathrm{G}_{\mathrm{ij}}\left(\mathrm{n}_{\mathrm{Ti}}, \mathrm{n}_{\mathrm{Rj}}\right)$ as the community of users in $\mathrm{n}_{\mathrm{Rj}}$ that retweet any of the users in $\mathrm{n}_{\mathrm{Ti}}$.

Finally, we computed the similarity coefficient in the same way that we did in the first step of the method, being 


$$
D_{i j k l}=\sigma\left(G_{i j}, G_{k l}\right)=\left|G_{i j} \cap G_{k l}\right| /\left|G_{i j} U G_{k l}\right|
$$

what we understand as a measure of similarity or distance between the set of users $\mathrm{A}_{\mathrm{NTi}}$ and $\mathrm{A}_{\mathrm{NTk}}$. Obviously, this distance can be calculated between any number of subsets of $\mathrm{N}_{\mathrm{T}}$ with different attributes.

\section{Results}

The retweet network is formed by those users that are linked when one of them retweets any other user's tweet. That is, the link $U_{i}$ to $U_{j}$ indicates that the user $U_{j}$ retweets the user $U_{i}$. To initially show whether political retweet networks show an homophilic character, we calculated the number of retweets to users of a given party that came from users of the same party, the number of retweets coming from other parties, and the percentage of the total retweets received by parties coming from political users (Table 7). As we have already indicated, we restricted the number of parties to those four that obtained the largest number of votes in the two past elections (PP, PSOE, Podemos and Cs). The four parties won almost $90 \%$ of the votes in both elections, and regional and nationalists parties, such as Esquerra Republicana de Catalalunya (Republican Left of Catalonia, ERC), and Democràcia i Llibertat (Democracy and Freedom, DiL) were excluded from negotiations (Simón, 2016).

\section{Table 7}

\section{Figure 1.1.}




\section{Figure 1.2}

Afterwards, we applied the RON method to the 1000 top retweeted users in \#20D and \#26J to analyse to what extent the RON networks were clustered (Figure 2).

\section{Figure 2.1}

\section{Figure 2.2}

We applied the RON method to calculate the similarities between the four parties in terms of the overlaps between the communities of retweeters of all the users for each party. We selected all the members of the four parties we previously identified. However, to improve the accuracy of our results, we extended our model by applying four different filters to the users of the communities of retweeters. Firstly, we calculated the similarity indexes by considering all the users that retweeted at least one post $\left(D_{1}\right)$. Afterwards, we applied the extended RON by using the type of user politician (or its absence) as the attribute. Thus, to avoid endogamic retweeting, we excluded politicians, $\left(D_{2}\right)$; politicians and media $\left(D_{3}\right)$; and, finally, politicians, media and journalists $\left(D_{4}\right)$. We assumed that, since media and politicians can have a different retweeting behaviour (Molyneux, 2015), the overlaps excluding them could significantly change. The results of the different distances of the extended RON are summarized in Table 8. 


\section{Table 8}

Finally, we also applied the extended RON to calculate the overlaps between groups of three parties, by applying the filters as we did before. Results are shown in Table 9.

\section{Table 9}

\section{Conclusions}

Retweeting, as an expression of people's will to spread and share someone else's messages, has also become one of the main focus of research on Twitter. Since the popularization of the microblogging site, there has been an intense debate around the causes that impel people to retweet messages. In particular, the dispute has been centered on the nature of a retweet as an endorsement of others' tweets. In this work, we have further explored the characteristics of retweeting by analysing the behavior of users in political debates in Spain. Our main hypothesis was that if we assume that in political conversations retweets are mainly endorsements, then the overlaps between the communities of retweeters of users and groups of users (in particular parties) can be understood as measures of similarity or distance between these users (Guerrero-Solé, Corominas-Murtra \& López-González, 2014). The resulting measures can be then added as new data in researches on coalition and government formation.

The results of our research show that the members of the four main political parties in Spain (PP, PSOE, Podemos and Cs) tended to retweet only messages from users of the same party, confirming H1. These results have been already observed in 
previous researches, and foster the positions that stress the functioning of social networks as echo chambers (Colleoni, Rozza \& Arvidsson, 2014; Jacobson, Myung \& Johnson, 2015) as well as the polarization of the political conversations in modern democracies. Despite we selected two presumably neutral samples, not ideologically biased, we found that almost 99 percent of the retweets of political users were made to other political users of the same party. Besides, the results show that there was almost no change between the elections in 2015 (20D) and in 2016 (26J). This reinforces the assumption that, at least for political users in political discussions, retweeting is, above all, a stable practice that can be understood as an act of endorsement (Metaxas et al., 2015). Previous research of the dynamics of Twitter during the 2011 Spanish political campaign already showed that the interaction between users was highly polarized, and political parties and leaders tended to use Twitter as a broadcast medium and barely interacted through replies with citizens (Aragón, Kappler, Kaltenbrunner, Laniado \& Volkovich; 2013).

Once proved the homophilic behaviour of political users in retweeting messages, we focused on the second hypothesis of the research. Thus, we analysed the retweet overlap network (RON), the network formed by the most influential users in terms of retweets received. The RON for the 1000 top retweeted users in 20D and 26J also confirmed that the networks were extremely clustered, since communities were already distinguishable for a threshold equal to 0 . However, the RON showed a difference between the networks in 20D and in 26J. While in the 2015 elections the clusters of the two left-wing political parties PSOE and Podemos were close to each other, in the 2016 elections PSOE's cluster is much closer to that of Cs, the centre-right party. As we already mentioned, Cs decided to support PSOE after the 2015 elections, and one of the 
consequences was that Podemos drifted apart from PSOE. The RON method shows that drift as well as the increase of the distance (or decrease of the similarity) between both parties.

The RON method performed well in measuring similarities that can explain political decisions in terms of coalition and government formation. In the Spanish 2015 election, there were three workable majorities that could be built by the PSOE, the formateur party (Simón, 2016): an alliance with Podemos and the abstention of Cs; an alliance with Cs and the abstention of Podemos; and a coalition with both Podemos and Cs. As we see in Table 8, PSOE and Podemos were the two parties with the greater index of similarity. However, the intra-party conflicts within PSOE and Podemos (the combination with the highest score of similarity in 20D) frustrated the first option and, finally, PSOE reached to an agreement with Cs (the second combination with the highest score for PSOE in 20D) despite they didn't win the investiture vote.

Our results show this increase of the distance between those parties, and the decrease of the distance between Cs and PSOE and PP. In this sense, Cs was considered as the most instrumental party to form a government, since it could come to an agreement either with PP or with PSOE, or with both. Cs represented the median party, that which helps to the formation of governments (Bäck \& Dumont, 2007). It is also shown that, in general, the further away the parties are ideologically, the larger the distance between them is. In particular, it is evident for PP (right) and Podemos (extreme left), and for Cs (centre-right) and Podemos. The same happened when we calculated the distances between three parties. Those combinations in which the extreme left was included were those with the smaller scores in terms of similarity. If we consider that the RON scores give us a valuable information about the real ideological 
distances, we have to take into account that the increase of these distances makes coalition formation difficult (Hinckley, 1972; Martin \& Vanberg, 2003; Volden \& Carrubba, 2004; Bäck \& Dumont, 2008). In that sense, both in 20D and 26J, the combination with the highest scores was that of PP, PSOE and Cs. It was three times higher than the rest of all the possible combinations, as it is shown in Table 9. This is precisely what president Rajoy considered the most reasonable thing (del Riego, 2016). Finally, this is what happened, since PP and Cs reached to an agreement, and PSOE, after an internal and fierce struggle, abstained in the vote to form Government despite it did not participate in the agreement (Simón, 2016). Furthermore, the similarity or closeness between the three parties grew substantially between 20D and 26J, confirming Spanish PM’s statement.

Since we observed that politicians and political parties tended to retweet to messages of the same party, and being aware of the characteristic retweeting behaviour of media and journalists, we excluded them to avoid biases related to these users by means of the extended RON method. But despite the value of the similarities changed, and in general grew (because of the decrease in the values of the denominators in the Jaccard index), no change was observed in relative terms. The closest parties in \#20D were PSOE and Podemos. After the first agreement between PSOE and Cs, the closest parties in \#26J became PP and Cs, and PSOE and Cs. The same happened for the combinations of three parties. Thus, we can consider that the similarities calculated are relatively stable despite the characteristics of the users that retweet political messages. Thus, our method leads to new metrics that ought to be considered in future researches and, significantly improves the previous method developed by Guerrero-Solé (2017). With this method, 
we can calculate the distances between groups of users (in our case, political parties) depending on certain characteristics of the users that retweet. But we can also filter the type of users retweeted by any category (official accounts, local accounts, politicians' accounts, male politicians, female politicians, and so on), and the type of users that retweet also by any category (politicians, media, journalists, gender). It can obviously lead to a large number of hypothesis and interpretations of users' retweet behaviour, and may help uncovering different latent attributes of the most influential users of a given network. In that same sense, Mölder (2017) used raw data from the manifesto project dataset (Volkens et al., 2015) to measure the index of similarity between parties, as a simple and effective way to explain differences between parties that may have an impact on the formation of coalitions and governments in multiparty democracies. For Mölder (2017), the index of similarity was a more reliable measure than the ideological position of parties, since the former tells us about the differences between two parties, and the latter about the location of parties severally. Thus, the RON method is intended to find a measure of similarity between parties considering the retweeting behavior of the users in Twitter.

In summary, despite politicians tend to only retweet messages from their own party, the retweeting behaviour of the users gives us a relevant information about the distances between parties. These distances can be obviously linked with ideology and, consequently, to the factors that can have an influence to coalition formation. However, we have also observed that the context can influence these distances, as proven by the differences between the results in 2015 and 2016, in particular in regards to the overlaps between PSOE and Podemos and PSOE and PP. 
Efforts may be put in the analysis of the behaviour of users in social networks and, in particular, in their retweeting behaviour. Since people consider their coalition preferences when voting (Plescia \& Aichholzer, 2017), and coalition signals lead them to strategic coordination (Gschwend, Stoetzer, \& Zittlau, 2016), we may also be aware of how voters' preferences have an influence on their behavior is social networks. This paper contributes to the knowledge and interpretation of the retweet behaviour of users in political discussions. It shows that the overlaps between the communities of retweeters of political parties can be linked to parties' willingness to reach political agreements (Guerrero-Solé, Corominas-Murtra \& López-González, 2014). Even more important is the fact that it shows that retweeting in political discussions is a stable behaviour, and that it can be interpreted as a support and an endorsement of users' messages. It is also an important finding, since the stabilization of the retweeting behaviour, at least for certain groups of users, can facilitate the interpretation of the overlaps between communities of retweeters and, finally, the relation between those users that are linked in the RON network.

This research is not without limitations. Firstly, we are subject to the biases of Twitter samples collected using the Twitter APIs (Morstatter, Pfeffer, Liu \& Carley, 2013; Tufekci, 2014). The API algorithms are black boxes (Bruns, 2012) that can obviate certain users and hierarchize them in terms of their influence in the network, and are not representative of the overall community of users nor of the total population. Secondly, the amount of data collected, half a million tweets and retweets for \#20D and \#26J, does not account for the whole political debate during the electoral campaigns. Thirdly, the samples were collected during the electoral campaigns, but we do not know 
anything about the evolution of users' behaviour after the elections and prior to the formation of the government. Besides, the RON method is also limited by the fact that it uses the Jaccard coefficient to calculate similarities. In future works we would need to explore other coefficients that can provide us with more information about how similar or close parties are. Finally, the results and hypothesis of this work should be completed by directly asking and analysing people and their retweeting behaviour in political discussions.

Conclusively, the RON method, and its extended version, worked well in predicting government formation in Spain, and it aims to be a contribution to the until now failing methods for explaining and predict the formation of real-world governments (Martin \& Stevenson, 2001) in political science. However, despite we found a rational link between retweeting overlaps and preferences for coalitions, unidimensional analysis have been largely criticized (Budge \& Keman, 1990) as a way to explain the formation of governments. It is naïve to think that retweet overlaps could explain everything in coalition formation; nonetheless, we argue that they may be taken into account by political parties and scholars as a measure of political distances. The distances and similarities that derive from social networks interactions (social media listening) in political discussions may be added as explaining variables in the models for predicting the formation of coalitions and governments in political science. 


\section{Authors Information}

Frederic Guerrero-Solé is an associate professor in sociology of communication at the Universitat Pompeu Fabra, Barcelona. His research interests include social networks, political communication, and media effects. Some of his recent works are Pacts with Twitter. Predicting voters' indecision and preferences for coalitions in multiparty systems (2014), and Community Detection in Political Discussions on Twitter: An Application of the Retweet Overlap Network Method to the Catalan Process Toward Independence (2017). Email: frederic.guerrero@upf.edu

Hibai Lopez-Gonzalez is a postdoctoral research fellow at the International Gaming Research Unit (IGRU) of Nottingham Trent University (UK). He is currently investigating the structural and persuasive characteristics of mediated sport content and 
sports betting advertising and their influence on sports betting behaviour, with emphasis on a problem gambling perspective. Email: hibai.lopezgonzalez@ntu.ac.uk

\section{References}

Aragón, P., Kappler, K. E., Kaltenbrunner, A., Laniado, D., \& Volkovich, Y. (2013). Communication dynamics in Twitter during political campaigns: The case of the 2011 Spanish national election. Policy and Internet, 5, 183-206. DOI:10.1002/19442866.POI327

Ausserhofer, J., \& Maireder, A. (2013). National politics on Twitter: Structures and topics of a networked public sphere. Information, Communication \& Society, 16, 291-314. DOI:10.1080/1369118X.2012.756050.

Bäck, H. (2003). Explaining and predicting coalition outcomes: Conclusions from studying data on local coalitions. European Journal of Political Research, 42, 441472. DOI:10.1111/1475-6765.00092 
Bäck, H., \& Dumont, P. (2007). Combining large-n and small-n strategies: The way forward in coalition research. West European Politics, 30, 467-501. DOI:10.1080/ 01402380701276295

Bäck, H., \& Dumont, P. (2008). Making the first move. A two-stage analysis of the role of formateurs in parliamentary government formation. Public Choice, 135, 353-373. DOI:10.1007/s11127-007-9267-5

Barberá, P., Jost, J. T., Nagler, J., Tucker, J. A., \& Bonneau, R. (2015). Tweeting From Left to Right: Is Online Political Communication More Than an Echo Chamber? Psychological Science, 26, 1531-42. DOI:10.1177/0956797615594620

Boutet, A., Kim, H., \& Yoneki, E. (2012). What's in twitter: I know what parties are popular and who you are supporting now! In Proceedings of the 2012 IEEE/ACM International Conference on Advances in Social Networks Analysis and Mining, 132-139. DOI:10.1109/ASONAM.2012.32

boyd, d., Golder, S., \& Lotan, G. (2010). Tweet, tweet, retweet: Conversational aspects of retweeting on twitter. In Proceedings of the Annual Hawaii International Conference on System Sciences. DOI:10.1109/HICSS.2010.412

Bruns, A. (2012). How long is a Tweet? Mapping Dynamic Conversation Networks on Twitter using GAWK and GEPHI. Information, Communication \& Society, 15, 1323-1351. DOI:10.1080/1369118X.2011.635214

Bruns, A., \& Burgess, J. (2012). Researching News Discussion on Twitter. Journalism Studies, 13, 801-814. DOI:10.1080/1461670X.2012.664428 
Bruns, A., \& Highfield, T. (2013). Political networks on Twitter: tweeting the Queensland state election. Information, Communication \& Society, 16, 667-691. DOI:10.1080/1369118X.2013.782328.

Budge, I., \& Keman, H. (1990). Parties and democracy: coalition formation and government functioning in twenty states. Comparative European Politics. DOI:10.1093/0198279256.001.0001

Casero-Ripolles, A., Feenstra, R. A., \& Tormey, S. (2016). Old and New Media Logics in an Electoral Campaign: The Case of Podemos and the Two-Way Street Mediatization of Politics. The International Journal of Press/Politics, 21, 378-397. DOI:10.1177/1940161216645340.

Ceron, A. (2016). Inter-factional conflicts and government formation Do party leaders sort out ideological heterogeneity? Party Politics, 22, 797-808. DOI:10.1177/ 1354068814563974

Ceron, A., \& D’Adda, G. (2016). E-campaigning on Twitter: The effectiveness of distributive promises and negative campaign in the 2013 Italian election, 18, 19351955. New Media \& Society. DOI:10.1177/1461444815571915

Ceron, A., Curini, L., \& Iacus, S. M. (2015). Using Sentiment Analysis to Monitor Electoral Campaigns: Method Matters--Evidence from the United States and Italy. Social Science Computer Review, 33, 3-20. DOI:10.1177/0894439314521983

CIS. Centro de Investigaciones Sociológicas. (2012). Barómetro Autonómico(III). Estudio ${ }^{\circ}$ 2.956. Retrieved from http://www.cis.es/cis/export/sites/default/Archivos/Marginales/2940_2959/2956/CATALUNA_9/Es2956Cat.pdf 
CIS. Centro de Investigaciones Sociológicas. (2015). Preelectoral Elecciones Generales 2015. Panel $\left(1^{\text {a }}\right.$ Fase $)$. Estudio $n^{\circ} 3117$. Retrieved from http://www.cis.es/cis/export/sites/default/Archivos/Marginales/3100_3119/3117/Es3117mar.pdf

Clauset, A., Shalizi, C. R., \& Newman, M. E. J. (2009). Power-Law Distributions in Empirical Data. SIAM Review, 51, 661-703.

Cohen, R., \& Ruths, D. (2013). Classifying Political Orientation on Twitter: It’s Not Easy! Seventh International AAAI Conference on Weblogs and Social Media, 91-99.

Colleoni, E., Rozza, A., \& Arvidsson, A. (2014). Echo chamber or public sphere? Predicting political orientation and measuring political homophily in Twitter using big data. Journal of Communication, 64, 317-332. DOI:10.1111/jcom.12084

Conover, M. D., Ratkiewicz, J., Francisco, M., Gonçalves, B., Flammini, A., \& Menczer, F. (2011) Political polarization on Twitter. ICWSM 133, 89-96. DOI:10.1021/ja202932e

Debus, M. (2009). Pre-electoral commitments and government formation. Public Choice, 138, 45-64. DOI: 10.1007/s11127-008-9338-2

Del Riego, C. (2016). Rajoy: “La aritmética lo soporta todo, pero lo razonable sería un gobierno de PP, PSOE y Ciudadanos”. Retrieved http://www.lavanguardia.com/politica/ 20160905/41120291500/mariano-rajoy-pppsoe-ciudadanos.html 
D’heer, E., \& Verdegem, P. (2014). Conversations about the elections on Twitter:

Towards a structural understanding of Twitter's relation with the political and the media field. European Journal of Communication, 29, 720-734. DOI:10.1177/ 0267323114544866

DiGrazia, J., McKelvey, K., Bollen, J., \& Rojas, F. (2013). More tweets, more votes: Social media as a quantitative indicator of political behavior. PLOS ONE 8. DOI:10.1371/journal.pone.0079449

Freelon, D., Lynch, M., \& Aday, S. (2015). Online Fragmentation in Wartime: A Longitudinal Analysis of Tweets about Syria, 2011-2013. The ANNALS of the American Academy of Political and Social Science, 659, 166-179. DOI:10.1177/0002716214563921

Gayo-Avello, D. (2012). "I Wanted to Predict Elections with Twitter and all I got was this Lousy Paper” -- A Balanced Survey on Election Prediction using Twitter Data. arXiv Preprint arXiv:1204.6441, 13. DOI:10.1234/12345678

Gayo-Avello, D. (2013). A Meta-Analysis of State-of-the-Art Electoral Prediction from Twitter Data. Social Science Computer Review, 31, 649-679. DOI:10.1177/ 0894439313493979

González-Bailón, S., Borge-Holthoefer, J., \& Moreno, Y. (2013). Broadcasters and Hidden Influentials in Online Protest Diffusion. American Behavioral Scientist, 57, 943-965. DOI:10.1177/0002764213479371 
Graham, T., Jackson, D., \& Broersma, M. (2016). New platform, old habits?

Candidates' use of Twitter during the 2010 British and Dutch general election campaigns. New Media \& Society, 18, 765-783. DOI:10.1177/1461444814546728

Grofman, B. (1982). A dynamic model of protocoalition formation in ideological nspace. Behavioral Science, 27, 77-90. DOI:10.1002/bs.3830270108

Grotz, F., \& Weber, T. (2016). New parties, information uncertainty, and government formation: evidence from Central and Eastern Europe. European Political Science Review, 8, 449-472. DOI:10.1017/S1755773915000120

Gschwend, T., Stoetzer, L., \& Zittlau, S. (2016). What drives rental votes? How coalitions signals facilitate strategic coalition voting. Electoral Studies, 44, 293-306. DOI:10.1016/j.electstud.2016.06.011

Guerrero-Solé, F., \& Mas-Manchón, L. (2017). Estructura de los tweets publicados durante las campañas electorales de 2015 y 2016 en España. El profesional de la información, 26, 805-815. DOI:10.3145/epi.2017.sep.03

Guerrero-Solé, F. (2017). Community detection in political discussions on Twitter. An application of the Retweet Overlap Network method to the Catalan process towards independence. Social Science Computer Review, 35, 244-261. DOI:10.1177/ 0894439315617254

Guerrero-Solé, F., Corominas-Murtra, B., \& López-Gónzalez, H. (2014). Pacts with Twitter. Predicting voters’ indecision and preferences for coalitions in multiparty systems. Information, Communication and Society, 17, 1280-1297. DOI:10.1080/ 1369118X.2014.920040 
Hemphill, L., Otterbacher, J., \& Shapiro, M. (2013). What's congress doing on Twitter? Proceedings of the 2013 Conference on Computer Supported Cooperative Work, 877. DOI:10.1145/2441776.2441876

Himelboim, I., McCreery, S., \& Smith, M. (2013). Birds of a Feather Tweet Together: Integrating Network and Content Analyses to Examine Cross-Ideology Exposure on Twitter. Journal of Computer-Mediated Communication, 18, 40-60. DOI:10.1111/jcc4.12001

Hinckley, B. (1972). Coalitions in Congress: Size and Ideological Distance. Midwest Journal of Political Science, 16, 197-207. DOI:10.2307/2110055

Huberty, M. (2015). Can we vote with our tweet? On the perennial difficulty of election forecasting with social media. International Journal of Forecasting, 31, 992-1007. DOI:10.1016/j.ijforecast.2014.08.005

Jacobson, S., Myung, E., \& Johnson, S. L. (2015). Open media or echo chamber: the use of links in audience discussions on the Facebook Pages of partisan news organizations. Information, Communication \& Society, 19, 875-891. DOI:10.1080/ 1369118X.2015.1064461

Juliana, E. (2016). Frankenstein no era inminente. Retrieved http://www.lavanguardia.com/politica/20161009/41867582761/pedro-sanchez-planpresidente-gobierno-apoyo-podemos-sobernaistas.html

Jungherr, A., Jürgens, P., \& Schoen, H. (2011). Why the pirate party won the German election of 2009 or the trouble with predictions: A response to Tumasjan, A., Sprenger, T. O., Sander, P. G., \& Welpe, I. M. "Predicting elections with Twitter: 
What 140 characters reveal about political sentiment”. Social Science Computer Review, 30, 229-234. DOI:10.1177/0894439311404119

Jungherr, A. (2014). The Logic of Political Coverage on Twitter: Temporal Dynamics and Content. Journal of Communication, 64, 239-259. DOI:10.1111/jcom.12087

Jungherr, A., Schoen, H., \& Jürgens, P. (2016). The Mediation of Politics through Twitter: An Analysis of Messages posted during the Campaign for the German Federal Election 2013. Journal of Computer-Mediated Communication, 21, 50-68. DOI:10.1111/jcc4.12143

Jungherr, A., Schoen, H., Posegga, O., \& Jürgens, P. (2016). Digital Trace Data in the Study of Public Opinion an Indicator of Attention Toward Politics Rather Than Political Support. Social Science Computer Review, 35, 336-356. DOI:10.1177/ 0894439316631043

Kim, M., \& Park, H. W. (2012). Measuring Twitter-based political participation and deliberation in the South Korean context by using social network and Triple Helix indicators. Scientometrics, 90, 121-140. DOI:10.1007/s11192-011-0508-5

La Fond, T., \& Neville, J. (2010). Randomization tests for distinguishing social influence and homophily effects. The 19Th International Conference, 601-610. DOI:10.1145/1772690.1772752

Larsson, A. O., \& Ihlen, Ø. (2015). Birds of a feather flock together? Party leaders on Twitter during the 2013 Norwegian elections. European Journal of Communication, 30, 666-681. DOI:10.1177/0267323115595525 
Larsson, A. O., \& Moe, H. (2013). Representation or participation? Twitter use during the 2011 Danish election campaign. Javnost, 20, 71-88.

Laver, M. (1998). Models of Government Formation. Annual Review of Political Science 1, 1-25. DOI:10.1146/annurev.polisci.1.1.1

Lee, E. J. (2013). Effectiveness of politicians' soft campaign on twitter versus TV: Cognitive and experiential routes. Journal of Communication, 63, 953-974. DOI:10.1111/jcom.12049

Liu, Z., Liu, L., \& Li H. (2012). Determinants of information retweeting in microblogging. Internet Research, 22, 443-466. DOI:10.1108/10662241211250980

Martin, L. W., \& Stevenson, R. T. (2001). Government Formation in Parliamentary Democracies. American Journal of Political Science, 45, 33-50.

Martin, L. W., \& Vanberg, G. (2003). Wasting Time? The Impact of Ideology and Size on Delay in Coalition Formation. British Journal of Political Science, 33, 323-332. DOI:10.1017/S0007123403000140

McPherson, M., Smith-Lovin, L., \& Cook, J. M. (2001). Birds of a Feather: Homophily in Social Networks. Annual Review of Sociology, 27, 415-444. DOI:10.1146/ annurev.soc.27.1.415

Metaxas, P. T., Mustafaraj, E., Wong, K., Zeng, L., Keefe, M. O., \& Finn, S. (2015). What do Retweets indicate? Results from User Survey and Meta-Review of Research. Association for the Advancement of Artificial Intelligence. 
Micó, J. L., \& Casero-Ripollés, A. (2014). Political activism online: organization and media relations in the case of $15 \mathrm{M}$ in Spain. Information, Communication \& Society, 17, 858-871. DOI:10.1080/1369118X.2013.830634

Mölder, M. (2017). Which measure of political difference between parties works better? A comparison in predicting coalition formation. Electoral Studies, 46, 26-38. DOI:10.1016/j.electstud.2016.12.004

Morstatter, F., Pfeffer, J., Liu, H., \& Carley, K. (2013). Is the sample good enough? Comparing data from Twitter's streaming API with Twitter's firehose. Proceedings of ICWSM, 400-408. DOI:10.1007/978-3-319-05579-4_10

Molyneux, L. (2015). What journalists retweet: opinion, humor, and brand development on Twitter. Journalism, 16, 920-935. DOI:10.1177/1464884914550135

Nick, B., Lee, C., Cunningham, P., \& Brandes, U. (2013). Simmelian backbones: Amplifying hidden homophily in Facebook networks. Advances in Social Networks Analysis and Mining (ASONAM), 525-532. DOI:10.1145/2492517.2492569

Orriols, L., \& Cordero, G. (2016). The Breakdown of the Spanish Two-Party System: The Upsurge of Podemos and Ciudadanos in the 2015 General Election. South European Society and Politics, 21, 469-492. DOI:10.1080/13608746.2016.1198454

Park, C. S. (2013). Does Twitter motivate involvement in politics? Tweeting, opinion leadership, and political engagement. Computers in Human Behavior, 29, 16411648. DOI:10.1016/j.chb.2013.01.044 
Parmelee, J. H. (2014). The agenda-building function of political tweets. New Media \& Society, 16, 434-450. DOI:10.1177/1461444813487955

Peng, T. Q., Liu, M., Wu, Y., \& Liu, S. (2016). Follower-Followee Network, Communication Networks, and Vote Agreement of the U.S. Members of Congress. Communication Research, 43, 996-1024. DOI:10.1177/0093650214559601

Plescia, C., \& Aichholzer, J. (2017). On the nature of voters’ coalition preferences, Journal of Elections, Public Opinion and Parties, 27, 254-273. DOI: $10.1080 / 17457289.2016 .1270286$

Plotkowiak, T., \& Stanoevska-Slabeva, K. (2013). German politicians and their twitter networks in the bundestag election 2009. First Monday, 18. DOI:10.5210/fm.v18i5.3816

Romero, D. M., Meeder, B., \& Kleinberg, J. (2011). Differences in the mechanics of information diffusion across topics. In Proceedings of the 20th international conference on World wide web, 695. DOI:10.1145/1963405.1963503

Schleiter, P., Belu, V., \& Hazell, R. (2017). Hung Parliaments and the Need for Clearer Rules of Government Formation. The Political Quarterly, 88, 404-411.

Simón, P. (2016). The Challenges of the New Spanish Multipartism: Government Formation Failure and the 2016 General Election. South European Society and Politics, 21, 493-517. DOI:10.1080/13608746.2016.1268292 
Skopek, J., Schulz, F., \& Blossfeld, H. P. (2011). Who contacts whom? Educational homophily in online mate selection. European Sociological Review, 27, 180-195. DOI:10.1093/esr/jcp068

Skoric, M., Poor, N., Achananuparp, P., Lim, E. P., \& Jiang, J. (2012) Tweets and Votes: A Study of the 2011 Singapore General Election. In Proceedings of the 45th Hawaii International Conference on System Sciences, 2583-2591. Maui: HI.

Thelwall, M. (2010). Emotion homophily in social network site messages. First Monday. DOI:10.5210/fm.v15i4.2897.

Tjong, E., Sang, K., \& Bos, J. (2012). Predicting the 2011 Dutch Senate Election Results with Twitter. In Proceedings of SASN 2012, the EACL 2012 Workshop on Semantic Analysis in Social Networks. Avignon, France.

Tufekci, Z. (2014). Big questions for social media big data: Representativeness, validity and other methodological pitfalls. In ICWSM '14: Proceedings of the 8th International AAAI Conference on Weblogs and Social Media, 505-514.

Tumasjan, A., Sprenger, T. O., Sandner, P. G., \& Welpe, I. M. (2010). Predicting Elections with Twitter. In Proceedings of the Fourth International AAAI Conference on Weblogs and Social Media, 178-185.

Vargo, C. J., Guo, L., McCombs, M., \& Shaw, D. L. (2014). Network Issue Agendas on Twitter During the 2012 U.S. Presidential Election. Journal of Communication, 64, 296-316. DOI:10.1111/jcom.12089 
Vercesi, M. (2016). Coalition Politics and Inter-Party Conflict Management: A Theoretical Framework. Politics and Policy, 44, 168-219. DOI:10.1111/polp.12154

Vergeer, M., \& Hermans, L. (2013). Campaigning on Twitter: Microblogging and Online Social Networking as Campaign Tools in the 2010 General Elections in the Netherlands. Journal of Computer-Mediated Communication, 18, 399-419. DOI:10.1111/jcc4.12023

Volden, C., \& Carrubba, C. J. (2004). The Formation of Oversized Coalitions in Parliamentary Democracies. American Journal of Political Science, 48, 521-537.

Volkens, A., Lehmann, P., Matthiess, T., Merz, N., Regel, S., \& Werner, A. (2015) The Manifesto Data Collection. Manifesto Project. Manifesto Project (MRG/CMP/MARPOR). DOI:10.25522/manifesto.mpds.2017a

Williams, H. T. P., McMurray, J. R., Kurz, T., \& Hugo Lambert, F. (2015). Network analysis reveals open forums and echo chambers in social media discussions of climate change. Global Environmental Change, 32, 126-138.

DOI:10.1016/j.gloenvcha.2015.03.006 
Table 1

Spaniards' opinion about the position of parties in the left (1) right (10) axis (2016)

\begin{tabular}{ll}
\multicolumn{1}{r}{ Parties } & Left-Right Axis \\
\hline Podemos & 2.19 \\
PSOE & 4.60 \\
Cs & 6.39 \\
PP & 8.35 \\
\hline
\end{tabular}

Source: CIS (2016) 
Table 2

Results of the Spanish Elections in December 2015 (20D) and June 2016 (26J). Percentages of votes and MPs obtained by Party in 20D and 26J

\begin{tabular}{lllll} 
& $20 \mathrm{D}$ & & 26J \\
Party & Percentage & MPs & Percentage & MPs \\
\hline PP & 28.72 & 123 & 33.03 & 137 \\
PSOE & 22.01 & 90 & 22.66 & 85 \\
Cs & 13.93 & 40 & 13.05 & 32 \\
Podemos & 20.66 & 69 & 21.10 & 71 \\
IU & 3.67 & 2 & & \\
\hline
\end{tabular}

Source: https://resultadosgenerales2015.interior.es/congreso/\#/ES201512-CON-ES/ES http://resultados2016.infoelecciones.es/99CO/DCO99999TO.htm?lang=es 
Table 3

Sample description for \#20D and \#26J

\begin{tabular}{|c|c|c|}
\hline & \#20D & \#26J \\
\hline Messages Collected & 540,849 & 576,842 \\
\hline Tweets & $110,523(20,4 \%)$ & $101,166(17,5 \%)$ \\
\hline Native Retweets & $430,326(79,6 \%)$ & $475,676(82,5 \%)$ \\
\hline
\end{tabular}

5000 Top Retweeted Users

$\%$ of total users

130,333 (3.8\%)

$114,620(4.4 \%)$

Retweeted times

404,056 (93,9\%)

460,492 (96,8\%) 
Table 4

Top 5000 users classification for \#20D and \#26J

\begin{tabular}{lcc} 
& \#20D & \#26J \\
& & \\
\hline Politicians & 1946 & 2202 \\
Media & 194 & 182 \\
Journalists & 225 & 213 \\
Citizens and Other & 2635 & 2403 \\
\hline
\end{tabular}


Table 5

Distribution of politicians by party for \#20D and \#26J

\begin{tabular}{lcc} 
Party & \#20D & \#26J \\
\hline Podemos & 525 & 605 \\
PSOE & 314 & 427 \\
Cs & 283 & 275 \\
PP & 438 & 567 \\
\hline
\end{tabular}


Table 6

Number of retweets received by party for \#20D and \#26J.

\begin{tabular}{lcc} 
Party & \#20D & \#26J \\
\hline Podemos & 44572 & 55760 \\
PSOE & 31784 & 76829 \\
Cs & 36318 & 39865 \\
PP & 32096 & 62613 \\
\hline
\end{tabular}


Table 7

Ratio of retweets received by parties from political users and ratio of retweets from political users of the total retweets received in \#20D and \#26J.

\begin{tabular}{llllll} 
Party & Podemos & PSOE & Cs & PP & Ratio total RT \\
\hline \#20D & & & & & \\
\hline Podemos & .994 & .004 & .001 & .001 & .531 \\
PSOE & .004 & .995 & 0 & 0 & .797 \\
Cs & 0 & 0 & .999 & .001 & .838 \\
PP & .002 & 0 & 0 & .998 & .810 \\
\hline \#26J & & & & & \\
Podemos & .996 & .002 & 0 & .001 & .626 \\
PSOE & .002 & .997 & 0 & .001 & .847 \\
Cs & 0 & 0 & .999 & 0 & .888 \\
PP & 0 & 0 & .001 & .999 & .894 \\
\hline
\end{tabular}


Table 8

RON distances between Spanish main political parties for \#20D and \#26J*.

\begin{tabular}{lllllllll}
\hline Parties & 20D $\mathrm{D}_{1}$ & $\mathrm{D}_{2}$ & $\mathrm{D}_{3}$ & $\mathrm{D}_{4}$ & 26J $\mathrm{D}_{1}$ & $\mathrm{D}_{2}$ & $\mathrm{D}_{3}$ & $\mathrm{D}_{4}$ \\
\hline PSOE-Podemos & $\mathbf{. 0 1 6 1}$ & $\mathbf{. 0 2 2 7}$ & $\mathbf{. 0 2 2 7}$ & $\mathbf{. 0 2 2 7}$ & .0066 & .0105 & .0104 & .0105 \\
PP-Cs & $\mathbf{. 0 1 0 5}$ & $\mathbf{. 0 1 5 1}$ & $\mathbf{. 0 1 5 1}$ & $\mathbf{. 0 1 5 0}$ & $\mathbf{. 0 3 5 8}$ & $\mathbf{. 0 4 6 2}$ & $\mathbf{. 0 4 6 0}$ & $\mathbf{. 0 4 6 3}$ \\
PSOE-Cs & .0043 & .0072 & .0071 & .0068 & $\mathbf{. 0 1 3 4}$ & $\mathbf{. 0 1 8 3}$ & $\mathbf{. 0 1 8 1}$ & $\mathbf{. 0 1 8 0}$ \\
Podemos-Cs & .0035 & .0048 & .0048 & .0048 & .0023 & .0030 & .0030 & .0031 \\
PP-PSOE & .0034 & .0055 & .0053 & .0053 & .0052 & .0087 & .0084 & .0085 \\
PP-Podemos & .0018 & .0046 & .0046 & .0046 & .0024 & .0035 & .0035 & .0035 \\
& & & & & & & & \\
\hline
\end{tabular}

* $\mathrm{D}_{1}$ considers all users, $\mathrm{D}_{2}$ excludes politicians, $\mathrm{D}_{3}$ excludes politicians and media, and $\mathrm{D}_{4}$ excludes politicians, media and journalists. 


\section{Table 9}

RON distances for groups of three Spanish political parties for \#20D and \#26J*.

\begin{tabular}{|c|c|c|c|c|c|c|c|c|}
\hline Parties & $20 \mathrm{D} \mathrm{D}_{1}$ & $\mathrm{D}_{2}$ & $\mathrm{D}_{3}$ & $\mathrm{D}_{4}$ & $26 \mathrm{~J} \mathrm{D}_{1}$ & $\mathrm{D}_{2}$ & $\mathrm{D}_{3}$ & $\mathrm{D}_{4}$ \\
\hline PSOE-Cs-PP & .0010 & .0011 & .0011 & .0011 & .0019 & .0024 & .0022 & .0023 \\
\hline Podemos-PSOE-Cs & .0008 & .0010 & .0010 & .0010 & .0006 & .0007 & .0007 & .0007 \\
\hline Podemos-PSOE-PP & .0006 & .0008 & .0008 & .0009 & .0007 & .0008 & .0008 & .0008 \\
\hline Podemos-Cs-PP & .0004 & .0007 & .0007 & .0007 & .0005 & .0006 & .0005 & .0005 \\
\hline
\end{tabular}


Figure 1.1. Retweet Network for \#20D (Profuse Force Directed layout). Red = PSOE, Purple $=$ Podemos, Orange $=$ Cs, Blue $=$ PP, Green $=$ Media and Journalists 
Figure 1.2. Retweet Network for \#26J (Profuse Force Directed layout). Red = PSOE, Purple $=$ Podemos, Orange $=$ Cs, Blue $=$ PP, Green $=$ Media and Journalists 
Figure 2.1. RON of the 1000 top retweeted users in \#20D (Profuse Force Directed layout $)$. Red $=$ PSOE, Purple $=$ Podemos, Orange $=$ Cs, Blue $=$ PP, Green $=$ Media and Journalists, Yellow and Dark Blue $=$ Catalan Nationalist Parties

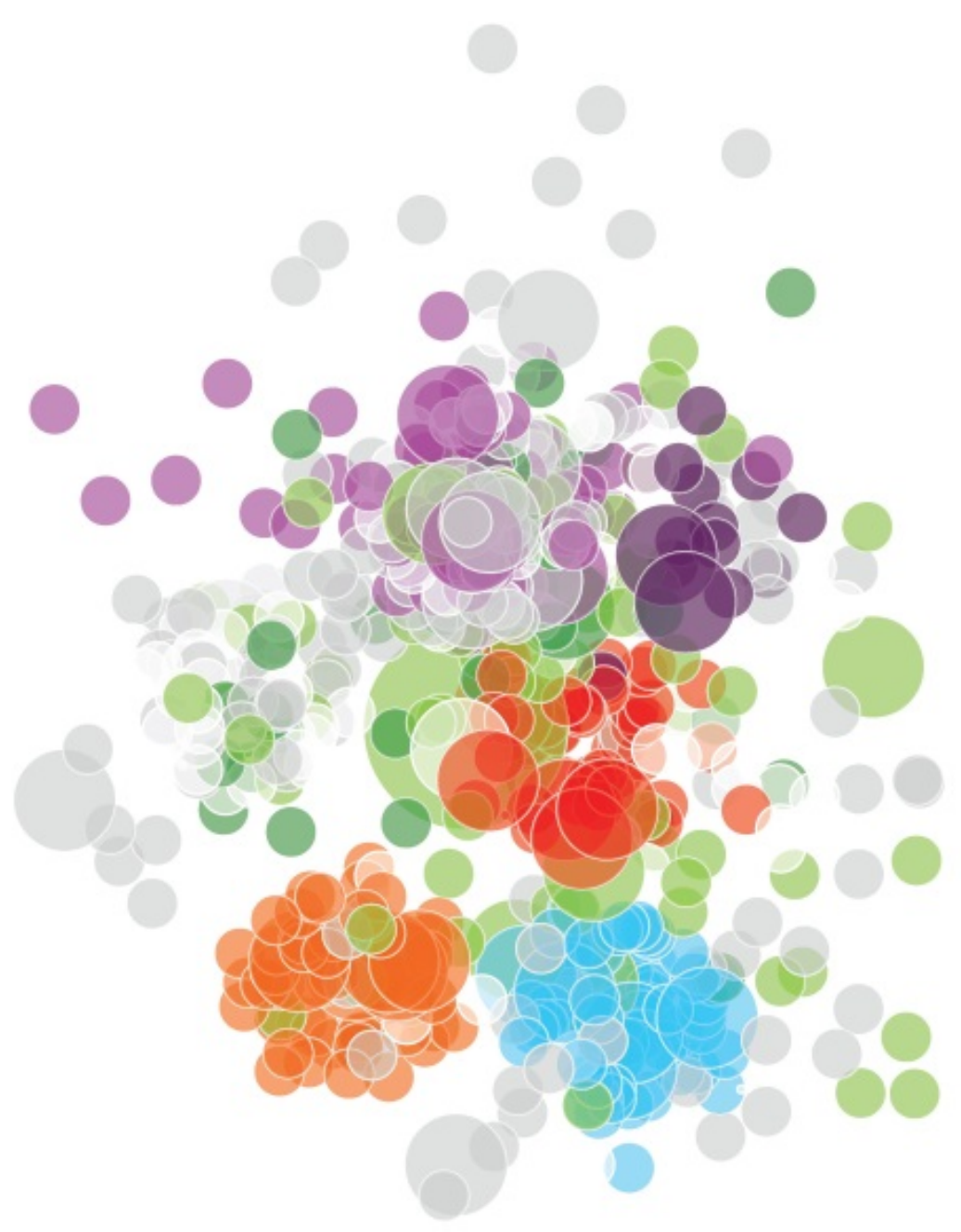


Figure 2.2. RON of the 1000 top retweeted users in \#26J (Profuse Force Directed layout $)$. Red $=$ PSOE, Purple $=$ Podemos, Orange $=$ Cs, Blue $=$ PP, Green $=$ Media and Journalists, Yellow and Dark Blue $=$ Catalan Nationalist Parties

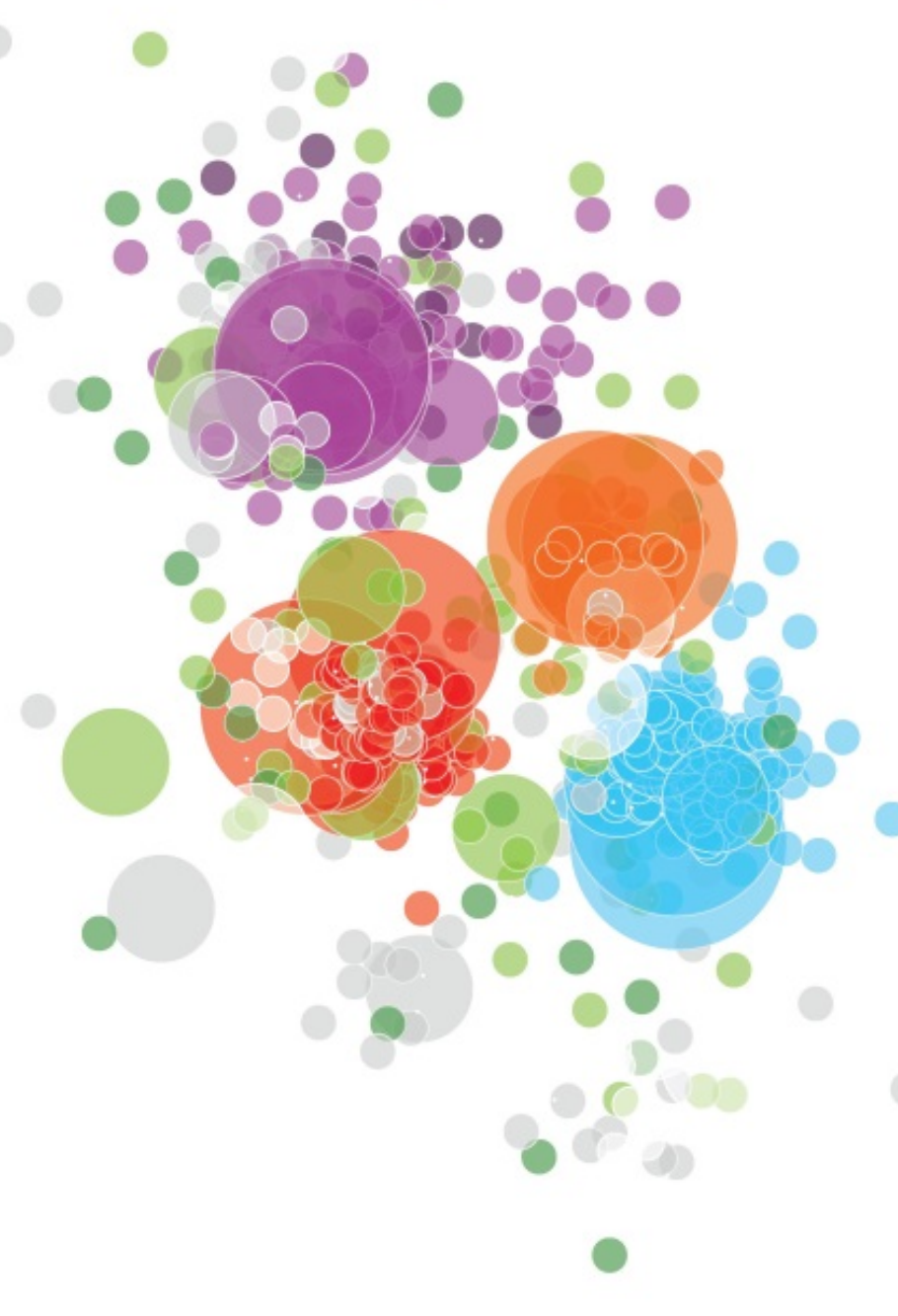

